\title{
Metabolic stratification driven by surface and subsurface interactions in a terrestrial mud volcano
}

\author{
Ting-Wen Cheng ${ }^{1,7}$, Yung-Hsin Chang ${ }^{1}$, Sen-Lin Tang ${ }^{2}$, Ching-Hung Tseng ${ }^{2}$, \\ Pei-Wen Chiang ${ }^{2}$, Kai-Ti Chang ${ }^{2}$, Chih-Hsien Sun ${ }^{3}$, Yue-Gau Chen ${ }^{1}$, Hung-Chi Kuo ${ }^{4}$, \\ Chun-Ho Wang ${ }^{5}$, Pao-Hsuan Chu ${ }^{1}$, Sheng-Rong Song ${ }^{1}$, Pei-Ling Wang ${ }^{6,7}$ and Li-Hung Lin ${ }^{1,7}$ \\ ${ }^{1}$ Department of Geosciences, National Taiwan University, Taipei, Taiwan; ${ }^{2}$ Biodiversity Research Center, \\ Academia Sinica, Taipei, Taiwan; ${ }^{3}$ Exploration and Development Research Institute, CPC Corporation \\ Taiwan, Miao-Li, Taiwan; ${ }^{4}$ Department of Atmospheric Sciences, National Taiwan University, Taipei, Taiwan; \\ ${ }^{5}$ Institute of Earth Sciences, Academia Sinica, Taipei, Taiwan and ${ }^{6}$ Institute of Oceanography, National \\ Taiwan University, Taipei, Taiwan
}

\begin{abstract}
Terrestrial mud volcanism represents the prominent surface geological feature, where fluids and hydrocarbons are discharged along deeply rooted structures in tectonically active regimes. Terrestrial mud volcanoes (MVs) directly emit the major gas phase, methane, into the atmosphere, making them important sources of greenhouse gases over geological time. Quantification of methane emission would require detailed insights into the capacity and efficiency of microbial metabolisms either consuming or producing methane in the subsurface, and establishment of the linkage between these methane-related metabolisms and other microbial or abiotic processes. Here we conducted geochemical, microbiological and genetic analyses of sediments, gases, and pore and surface fluids to characterize fluid processes, community assemblages, functions and activities in a methane-emitting MV of southwestern Taiwan. Multiple lines of evidence suggest that aerobic/ anaerobic methane oxidation, sulfate reduction and methanogenesis are active and compartmentalized into discrete, stratified niches, resembling those in marine settings. Surface evaporation and oxidation of sulfide minerals are required to account for the enhanced levels of sulfate that fuels subsurface sulfate reduction and anaerobic methanotrophy. Methane flux generated by in situ methanogenesis appears to alter the isotopic compositions and abundances of thermogenic methane migrating from deep sources, and to exceed the capacity of microbial consumption. This metabolic stratification is sustained by chemical disequilibria induced by the mixing between upward, anoxic, methane-rich fluids and downward, oxic, sulfate-rich fluids.

The ISME Journal (2012) 6, 2280-2290; doi:10.1038/ismej.2012.61; published online 28 June 2012

Subject Category: geomicrobiology and microbial contributions to geochemical cycles

Keywords: metabolic stratification; terrestrial mud volcano; sulfate-to-methane transition zone; methanogenesis; 16S rRNA gene clone library; metagenome
\end{abstract}

\section{Introduction}

Mud volcanoes (MVs) and hydrocarbon seepages are ubiquitous in both marine and terrestrial environments. They are characterized by continuous or episodic discharges of gaseous fluids with unconsolidated, fine-grained sediments generated during clay dehydration, compaction dewatering or tectonic pressurization at depth (Kopf, 2004). These surface expressions often represent the outlet of fluid conduits that tap into deep petroleum and natural

Correspondence: T-W Cheng or L-H Lin, Department of Geosciences, National Taiwan University, Taipei, Taiwan.

E-mail: akira.sch@gmail.com (T-WC) or lhlin@ntu.edu.tw (L-HL) or P-L Wang, Institute of Oceanography, National Taiwan University, Taipei, Taiwan.

E-mail: plwang@ntu.edu.tw

${ }^{7}$ These authors contributed equally to this work.

Received 16 December 2011; revised 7 May 2012; accepted 10 May 2012; published online 28 June 2012 gas reservoirs, thereby providing an accessible window to probe the characteristics of petroleum and gas sources, and the deep biosphere. Methane appears to be the major gaseous constituent released from most MVs. Recent estimates indicate that MVs and seepages onshore and offshore around the world might account for approximately $30 \%$ of the methane emission from natural sources (Etiope et al., 2008). Considering the huge capacity of methane potentially stored in the subterranean or subseafloor strata (Milkov, 2004), these geological sources might have been an important factor diverting the redox equilibrium in the atmosphere over geological time. Terrestrial MVs particularly have a vital role as methane and other hydrocarbons are directly released into the atmosphere. Therefore, any assessment of the greenhouse effect on a global scale has to consider the contribution of terrestrial MVs. 
Stable isotopic and molecular compositions of hydrocarbons have been broadly utilized to identify the hydrocarbon origin and to trace the hydrocarbon migration (Whiticar, 1990; Etiope et al., 2009; Sun et al., 2010). On the basis of $\delta^{13} \mathrm{C}-\mathrm{CH}_{4}$ and $\delta^{2} \mathrm{H}-\mathrm{CH}_{4}$ values, about $25 \%$ out of 143 studied MVs around the world release microbial methane or a mixture of microbial and thermogenic methane (Etiope et al., 2009). In contrast, a plot of the same data set on the $\delta^{13} \mathrm{C}-\mathrm{CH}_{4}$ versus $\mathrm{C}_{1} /\left(\mathrm{C}_{2}+\mathrm{C}_{3}\right)$ diagram shows that most terrestrial MVs produce gas signals falling within an ambiguous sector due to post-genetic processes, such as microbial oxidation, mixing or molecular fractionation during migration (Etiope et al., 2009). This contradictory interpretation illustrates the complexity in the identification of gas origin, as well as strengthens the importance of the post-formational microbial process at shallow depths.

Only limited studies have been conducted to investigate microbial activities and community structures in terrestrial, methane-rich MVs (Alain et al., 2006; Chang et al., 2012; Wrede et al., 2012). These studies reveal that archaeal communities are primarily composed of anaerobic methanotrophs (ANME groups for ANaerobic Methanotrophic Euryarchaeota) with different fractions of methanogens or Crenarchaeaota. Bacterial communities consist of diverse members taxonomically distributed across various phyla. The rates of methanogenesis and sulfate reduction, however, outnumber those of anaerobic oxidation of methane (AOM) by one to two orders of magnitude (Alain et al., 2006). In addition, the correlation between geochemical profiles and community assemblages for sediments collected from the mud platform surrounding a bubbling pool suggests that AOM might be coupled to metal reduction (Chang et al., 2012). These results demonstrate a variety of potential electron-accepting processes involved in organic degradation and/or methanotrophy, and are in contrast with the predominance of ANME members and sulfate reducers, and high sulfate-dependent methanotrophic activities in marine hydrocarbon seepages (Boetius et al., 2000; Orphan et al., 2002; Treude et al., 2005; Knittel and Boetius, 2009). In terrestrial settings, sulfate abundances are generally much lower than in seawater. Whether sulfate-dependent metabolisms are active and how methane-related metabolisms interact with the imposed geochemical context in terrestrial MVs are not clear.

This study aimed to uncover the key microbial and abiotic processes associated with the subsurfacesurface interactions that shaped the cycling of methane and other related compounds in terrestrial, methane-rich MVs. Using samples collected from the Shin-Yan-Ny-Hu MVs (SYNHMV) in southwestern Taiwan, geochemistry of pore water and gases, $16 \mathrm{~S}$ rRNA gene diversity, abundance of functional genes extracted from metagenome data and culturing were integrated to constrain the spectrum of metabolic capability along a vertical profile.

\section{Materials and methods}

\section{Study site and sample collection}

The SYNHMV is located in the Yan-Chou area of southwestern Taiwan (Supplementary Information and Supplementary Figure S1) and comprises a cone-shaped structure (SYNH01) and a bubbling mud pool (SYNH02) (Figure 1). Muddy fluids mixed with abundant hydrocarbon gases are discharged out of the cone and pool, and drained toward the topographic depression. The fluid flux varies from time to time on the basis of visual inspection.

The majority of samples were collected from the bubbling pool SYNH02 and its surrounding mud platform. Two field campaigns were conducted in 2007 and 2009. Before sample collection, several parameters (including temperature, conductivity, redox potential and $\mathrm{pH}$ ) of bubbling and surface fluids were measured on site using the portable probes (WTW Multi 340i, Weilheim, Germany). Samples were collected from sediments retrieved by push-coring (core c1 in 2007, cores c2 and c3 in 2009), and from bubbling fluids (ew01 and ew02 in 2009) and surface fluids along an outflow channel (sw01 to sw06 in 2009) (Figure 1). Core c1 was retrieved for pilot analyses of anions and methane. Core c2 was used for detailed analyses of aqueous, gas and isotope geochemistry, whereas core c3 was used for incubation experiments and molecular analyses. All samples were processed in the field, stored in sterile containers with/without preservatives and shipped back to the laboratory either on dry ice (samples for molecular analyses) or at ambient temperature (samples for aqueous and gas chemistry and incubations). Detailed descriptions for sample processing and geochemical analyses can be found in Supplementary Information.

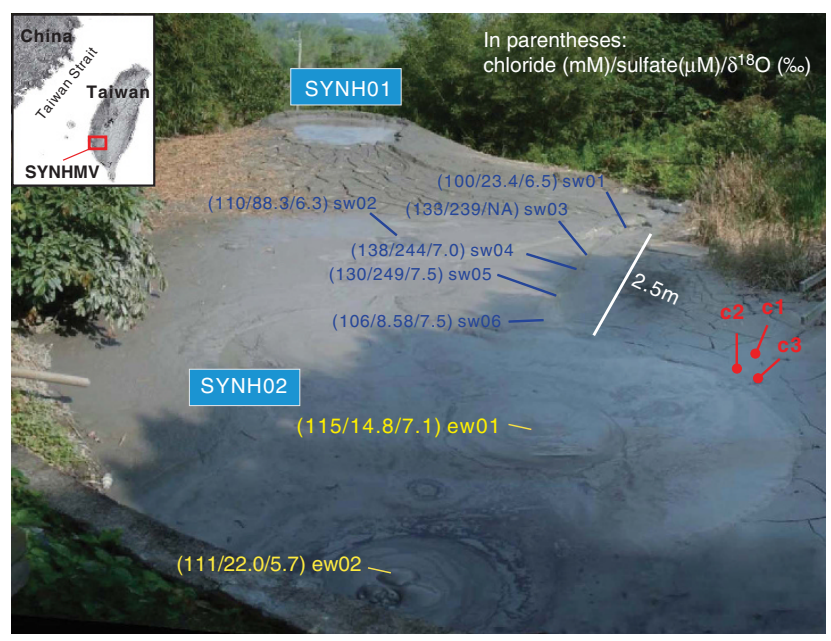

Figure 1 Field image of the SYNHMV (viewed toward northwest). Samples are categorized into cores (labeled 'c' in red), bubbling fluids (labeled 'ew' in yellow) and surface fluids in an outflow channel (labeled 'sw' in blue). The prominent geochemical features (including chloride $(\mathrm{mM})$, sulfate $(\mu \mathrm{M})$ and $\delta^{18} \mathrm{O}(\%$ VSMOW)) are shown in parentheses. 
$16 S$ rRNA gene analysis

Genomic DNA for 16S rRNA gene analyses was extracted from 10-g sediments (from 1, 7, 11, 23 and $31 \mathrm{~cm}$ of core c3) and the bubbling fluid (ew01), using the UltraClean Mega Soil DNA Isolation Kit (MoBio Laboratories, Carlsbad, CA, USA) according to the manufacturer's instruction, and stored at $-20^{\circ} \mathrm{C}$. Nearly complete $16 \mathrm{~S}$ rRNA gene sequences were amplified on a Robocycler (Stratagene, La Jolla, CA, USA), using a bacterial forward primer B27F and a universal reverse primer U1492R for bacteria (Lane, 1991), and an archaeal forward primer A8F and a universal reverse primer U1513r for archaea (Huber et al., 2002). The PCR protocol and downstream approaches for purification of PCR products, cloning and sequencing were described previously (Lin et al., 2006). The obtained sequences were checked for chimera formation using Pintail (Ashelford et al., 2005). Sequences sharing $\geqslant 98 \%$ pairwise sequence identity were assigned to the same phylotype, and the nearest relative of each phylotype was retrieved from NCBI using the BLAST tool. The accession numbers of the obtained sequences deposited in GenBank were from JQ245511-JQ245695.

\section{Metagenomic analysis}

Genomic DNA in sediments from 3, 13, 23 and $31 \mathrm{~cm}$ of core c3 was obtained through phenol-chloroform extraction, and amplified using the Illustra Genomiphi V2 DNA Amplification Kit (GE Healthcare, Piscataway, NJ, USA). A total of $5 \mu \mathrm{g}$ of the amplified DNA was sent to the Mission Biotech (Taipei, Taiwan) for high throughput pyrosequencing by a Roche 454 Genome Sequencer Titanium System (Roche/454 Life Sciences, Branford, CT, USA). The sequences were assembled with $99 \%$ identity in the overlapping region (40 bases) using the manufacturer's assembler. To compare the numbers of key functional genes, R (v.2.10.1; RDC Team, 2008) and the built-in statistic package were used to perform a clustering analysis. Genes subject to further analyses include apr (encoding adenosine-5'-phosphosulfate reductase), $d s r$ (encoding dissimilatory sulfite reductase), mcr (encoding methyl coenzyme M reductase) and $\mathrm{mmo} / \mathrm{pmo}$ (encoding soluble and particulate methane monooxygenase). The read counts of each gene from different depths were calculated and standardized by the $Z$-score method (Supplementary Information). Sequences obtained in this study were deposited in the NCBI Short Read Archive with the accession numbers of SRR389126 $(31 \mathrm{~cm})$, SRR389127 $(23 \mathrm{~cm})$, SRR389128 $(13 \mathrm{~cm})$ and SRR389129 $(3 \mathrm{~cm})$.

\section{Incubation experiment}

Sediments (5 $\mathrm{ml}$ or 8-10g) collected by cutoff syringes were inoculated into serum bottles $(59 \mathrm{ml})$ containing the designated medium adjusted to the local salinity $(20 \mathrm{ml}$; ingredients include $5.8 \mathrm{~g} \mathrm{NaCl}$,
$0.4 \mathrm{~g} \mathrm{MgCl}_{2} .6 \mathrm{H}_{2} \mathrm{O}, 0.3 \mathrm{~g} \mathrm{KCl}, 0.15 \mathrm{~g} \mathrm{CaCl}_{2} .2 \mathrm{H}_{2} \mathrm{O}$, $0.27 \mathrm{~g} \mathrm{NH}_{4} \mathrm{Cl}$ and $0.2 \mathrm{~g} \mathrm{KH}_{2} \mathrm{PO}_{4}$ per liter of medium at $\mathrm{pH}$ 7.2) and flushed with pure argon for $2 \mathrm{~min}$ on site. The mineral solution was supplied with $10 \mathrm{~mm}$ sulfate for sulfate reduction or sulfate-dependent AOM, $5 \mathrm{~mm}$ acetate for acetoclastic methanogenesis and $5 \mathrm{~mm}$ methanol and methylamine each for methylotrophic methanogenesis. Bicarbonate at a final concentration of $10 \mathrm{~mm}$ was supplied for aerobic methanotrophy. Specific gases were provided for target metabolisms back in the laboratory. For aerobic methane oxidation, the headspace was flushed with air with a total volume five times the headspace volume $(\sim 35 \mathrm{ml})$, and provided with $3 \mathrm{ml} 100 \%$ methane (equivalent to $\sim 8200 \mathrm{~Pa}$ ). For sulfate reduction, and acetoclastic and methylotrophic methanogenesis, the headspace gas was replaced with pure nitrogen. For hydrogenotrophic methanogenesis, the headspace gas was replaced with a gas mixture of $90 \% \quad \mathrm{H}_{2}$ and $10 \% \quad \mathrm{CO}_{2}$. Samples for AOM were flushed with pure nitrogen first, and supplied with $5 \mathrm{ml}{ }^{13} \mathrm{C}$-labeled methane (equivalent to $\sim 13000 \mathrm{~Pa}$ ). The incubations were performed at room temperature $\left(\sim 25^{\circ} \mathrm{C}\right)$ in the dark. Methane, sulfate and ${ }^{13} \mathrm{CO}_{2}$ were monitored for methanogenesis/aerobic methanotrophy, sulfate reduction and AOM through time, respectively. The accumulated yields of methane in the methanogenic incubations were further plotted against time to derive the initial methane production rate (within 3 days) used to constrain the maximum in situ methanogenic activity.

Quantification of consumption and production rates of sulfate and methane

The general diagenetic equation for reactive transport was used to model the solute transport and microbial reaction rate in the sediment column:

$$
\frac{\partial C_{\mathrm{i}}}{\partial t}=\phi D_{\mathrm{sed}} \frac{\partial^{2} C_{\mathrm{i}}}{\partial z^{2}}-\phi v \frac{\partial C_{\mathrm{i}}}{\partial z}+R_{\mathrm{i}}
$$

where $C_{\mathrm{i}}$ is the solute species $\mathrm{i}$ of interest, $t$ is the time, $z$ is the depth, $\varphi$ is the porosity, $D_{\text {sed }}$ is the diffusivity corrected for tortuosity, $v$ is the advection rate, and $R$ is the net reaction rate. Concentration and porosity data used in the modeling were adopted from the measurements. The correction of diffusivity for tortuosity followed the empirical relationships reported previously (Wang et al., 2008b). The modeling further assumed that sedimentation and compaction rates were zero and a steady state was reached within a definitive time scale so the term $\partial C_{i} / \partial t$ was zero. The programs (NRR1 and NRR2) developed by Wang et al. (2008b) were employed to derive the predicted concentrations and net reaction rates for sulfate and methane.

Given that chloride is soluble and inert to most abiotic and biological reactions in ambient environments, the reaction term $\left(R_{\mathrm{i}}\right)$ for chloride in the general diagenetic equation could be omitted. The 

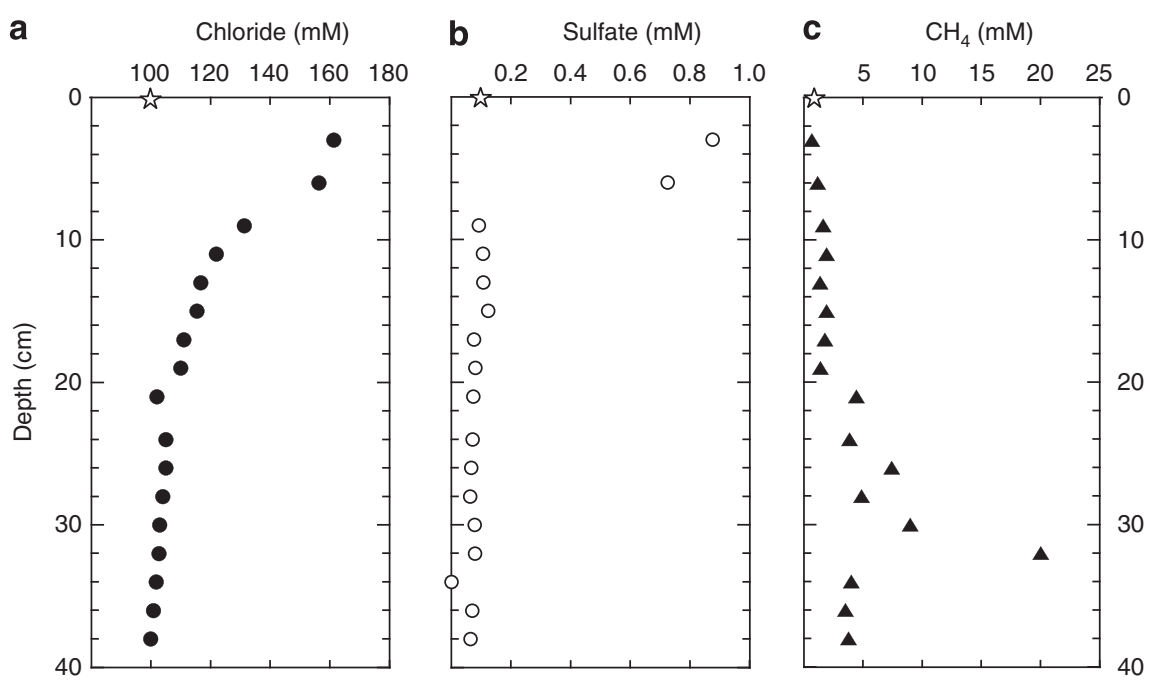

Figure 2 Concentrations of chloride (a), sulfate (b), and methane (c) in pore water of core c1 collected in 2007. Open-star symbols represent the compound concentrations in the bubbling fluid.

chloride profile was then used to compute the advection rate. Integration over diffusion and advection terms demonstrated that chloride varied exponentially with depth. The best fit to the observed chloride profile required fluid advection at a rate of $0.10 \pm 0.03 \mathrm{~m}$ per year. However, the profile predicted simply by diffusion and advection transport could not replicate the observed chloride concentrations at shallow depths. This is most likely because evaporation at the surface and shallow depths enhances solute concentrations. The net reaction rates for sulfate and methane were further calculated using the advection rate of $0.1 \mathrm{~m}$ per year.

\section{Results}

Geochemical characteristics

The bubbling fluid with a temperature of $23.6{ }^{\circ} \mathrm{C}$ was alkaline ( $\mathrm{pH}$ 8.36), reducing $\left(E_{\mathrm{h}}-340 \mathrm{mV}\right)$, moderately saline $(\sim 110 \mathrm{~mm}$ chloride) and low in sulfate $(<30 \mu \mathrm{M}$; Figure 1 and Supplementary Table S1). Sulfate $(8.6-249 \mu \mathrm{M})$ and chloride (100-138 mm) concentrations in the surface fluids along an outflow channel were variable. The $\delta^{18} \mathrm{O}$ values of the bubbling and surface fluids spanned from 6.3 to $7.5 \%$ (Figure 1), a range greater than those of local meteoric water and similar to those of the bubbling fluids collected from other MVs in southwestern Taiwan (Supplementary Figure S2). Methane concentrations in the bubbling fluids ranged from 0.7 to $0.9 \mathrm{~mm}$ (roughly equivalent to $50-64 \%$ partial pressure of methane in the gas phase). The $\delta^{13} \mathrm{C}$ values of methane in the bubbling fluid were around $-34.5 \%$ (Supplementary Table S1). Ethane and propane concentrations in the bubbling fluids were from 28 to $31 \mu \mathrm{M}$ and from 8.6 to $9.3 \mu \mathrm{M}$, respectively.

Pilot analyses of pore water samples collected in 2007 showed that sulfate and chloride concentrations decreased with depth (Figure 2). Although sulfate was nearly depleted below $9 \mathrm{~cm}$, chloride concentrations decreased from $161 \mathrm{~mm}$ at the top to $100 \mathrm{~mm}$ at $38 \mathrm{~cm}$. In contrast, methane concentrations increased with depth and peaked at $32 \mathrm{~cm}$ $(20 \mathrm{~mm})$. These data showing a sulfate-methane transition zone (SMTZ) at $9-20 \mathrm{~cm}$ prompted detailed geochemical analyses of samples collected in 2009. Chloride and sulfate profiles in 2009 (Figure 3 and Supplementary Table S2) exhibited a pattern similar to those in 2007. Chloride concentrations gradually decreased with depth. Sulfate concentrations decreased from $4.1 \mathrm{~mm}$ at the top to $<10 \mu \mathrm{M}$ at depths below $10 \mathrm{~cm}$. The depletion of sulfate was accompanied with an increase of methane. Below $\sim 20 \mathrm{~cm}$, the methane concentrations varied substantially between 1.29 and $2.14 \mathrm{~mm}$. The $\delta^{13} \mathrm{C}$ values of methane decreased from $-39 \%$ at the top to $-48 \%$ at the deepest interval. Ethane concentrations remained at a nearly constant level over most depth intervals, whereas propane concentrations decreased with depth. Both ethane and propane concentrations were one to two orders of magnitude less than those of methane. Although alkalinity decreased with depth, the $\delta^{13} \mathrm{C}$ values of dissolved inorganic carbon exhibited a U-shaped profile with the lowest value of $4.3 \%$ at the SMTZ and the high values of $7.1-7.3 \%$ at the deepest and top intervals.

\section{Compositions of $16 \mathrm{~S}$ rRNA gene}

A total of 402 archaeal and 668 bacterial 16S rRNA gene clone sequences were obtained from the bubbling fluid and sediments, and clustered into 36 and 149 phylotypes (98\% similarity cutoff), respectively (Figure 4 and Supplementary Table S3). Of the archaeal members, $>60 \%$ of any individual library comprised sequences affiliated with methanogens (Figure 4). The majority of methanogens related to these sequences switched from Methanosarcinales (Methanosaeta- and Methanolobus-related strains) at $\leqslant 7 \mathrm{~cm}$ to Methanomicrobiales (Methanoculleus- and 

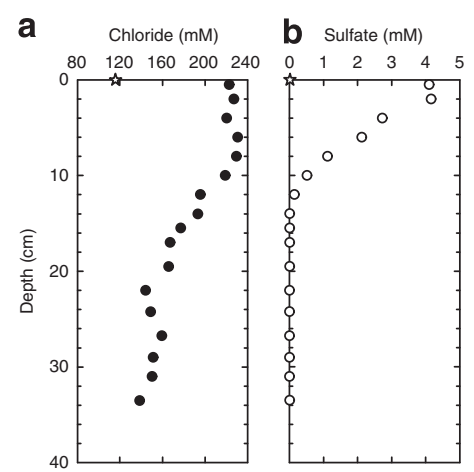

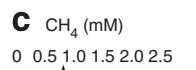

Alkalinity $(\mathrm{mM})$ $\begin{array}{llllll}30 & 40 & 50 & 60 & 70 & 80\end{array}$

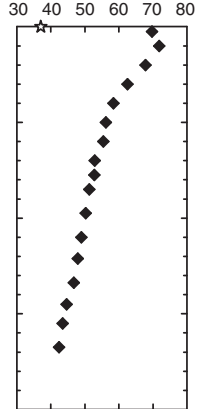

$\mathbf{e}_{\delta^{13} \mathrm{C}-\mathrm{CH}_{4}(\%)}$

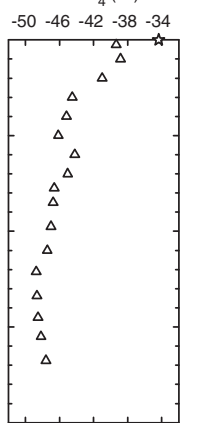

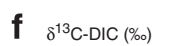

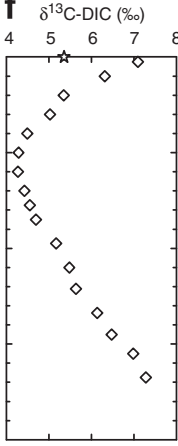

g $\mathrm{C}_{2} \mathrm{H}_{6}(\mu \mathrm{M})$

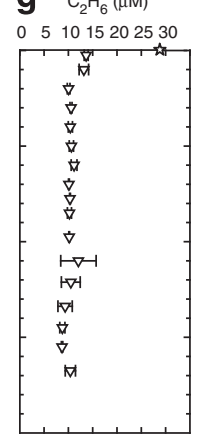

h $\mathrm{C}_{3} \mathrm{H}_{8}(\mu \mathrm{M})$

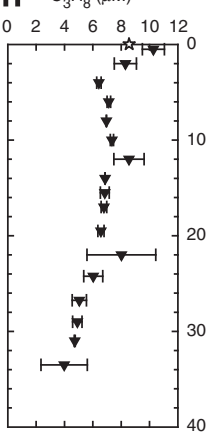

Figure 3 Concentrations of chloride (a), sulfate (b), methane (c), and alkalinity (d), carbon isotopic compositions of methane (e) and DIC (f), and concentrations of ethane (g) and propane (h) in pore water of core c2 collected in 2009. DIC stands for dissolved inorganic carbon. Gas abundances in (c), (g) and (h) were averaged over triplicate samples from the same intervals. The error bar represents one s.d. Openstar symbols represent the compound concentrations in the bubbling fluid.

Methanocalculus-related strains) at $\geqslant 11 \mathrm{~cm}$. Some archaeal sequences (1-9\%) in the bubbling fluid and at $7 \mathrm{~cm}$ were affiliated with the ANME-1 group.

Bacterial community assemblages varied substantially among samples (Figure 4 and Supplementary Table S3). Phylum-based categorization indicated that the decrease in Cyanobacteria and GammaProteobacteria was accompanied with an increase in Firmicutes and Bacteroidetes as the depth increased. The dominant sequences $(>10 \%$ of each clone library) were affiliated with hydrocarbondegrading Syntrophorhabdus sp. (Qiu et al., 2008) and Alcanivorax sp. (Wang et al., 2008a), heterotrophic Marinobacter sp. (Zhang et al., 2002), Tindallida sp. (Alazard et al., 2007), Pseudomonas sp., Clostridium sp. (Shiratori et al., 2009) and Alkaliflexus imshenetskii (Zhilina et al., 2004), mixotrophic Hydrogenophaga sp. (Kämpfer et al., 2005) and uncultured Bacteroidetes. Sequences affiliated with sulfate reducing Desulfobacterales (Kuever et al., 2005), Desulfonatronum sp. (Zhilina et al., 2005), and Desulfovibrio sp. (Abildgaard et al., 2006), and sulfur oxidizing Thiomicrospira sp. (Brinkhoff and Muyzer, 1997) and Thioalkalispira sp. (Sorokin et al., 2002) were also detected in the sediments (Figure 4). Despite variations in sediment community assemblage, sequences affiliated with thermophilic Thermococcus mexicalis (Lepage et al., 2004), Methanosaeta thermophila (Kamagata et al., 1992), Pelotomaculum thermopropionicum (Imachi et al., 2002) and Thermodesulfovibrio yellowstoni (Henry et al., 1994) were either exclusively present or more abundant in the bubbling fluid.

\section{Functional genes in metagenome}

Metagenome data with a total of 495960,488597 , 335045 and 511350 reads were obtained from sediments at $3,13,23$ and $31 \mathrm{~cm}$, respectively (Supplementary Table S4). The summed read length was roughly equivalent to a total of $583 \mathrm{Mbps}$. Abundances of the genes mmo/pmo, apr and dsr at 3 and $13 \mathrm{~cm}$ were greater than those at 23 and $31 \mathrm{~cm}$ (Figure 5). In contrast, abundance of the gene mcr peaked at $23 \mathrm{~cm}$, was maintained at a moderate level at 3 and $13 \mathrm{~cm}$, and decreased to a low level at $31 \mathrm{~cm}$.

\section{Incubation experiments}

Methane was produced in incubations supplied with methanogenic precursors $\left(\mathrm{H}_{2} / \mathrm{CO}_{2}\right.$, acetate and methanol/methylamine) for sediments collected from all investigated depth intervals. The initial methanogenic rates for the incubations supplied with methylamine/methanol ranged between 2 to $4 \mathrm{nmol} \mathrm{h}^{-1} \mathrm{~g}^{-1}$ at $4-21 \mathrm{~cm}$, and decreased to $0.5 \mathrm{nmol} \mathrm{h}^{-1} \mathrm{~g}^{-1}$ at three deepest intervals (Figure 6). The initial methanogenic rates for the incubations supplied with acetate increased with depth with high values (2 to $5 \mathrm{nmol} \mathrm{h}^{-1} \mathrm{~g}^{-1}$ ) occurring at $20-30 \mathrm{~cm}$, whereas those with $\mathrm{H}_{2} / \mathrm{CO}_{2}$ exhibited two peak zones near the SMTZ and at $25 \mathrm{~cm}$.

Methane was aerobically consumed in incubations of sediments from all investigated depth intervals. Initial methane in headspace $\left(\sim 8 \times 10^{4}\right.$ p.p.m.v.) was reduced to a level below 500 p.p.m.v. within 2 weeks for sediments from nearly all investigated depth intervals (except for sediments at $25 \mathrm{~cm}$ ). As the headspace was episodically supplied with air during incubation and the internal pressure was not monitored, methane consumption rate could not be precisely calculated.

Sulfate reduction was slow in sulfate-supplied incubations of sediments from all investigated depth intervals. The addition of a mixture of yeast extract, peptone and trypton stimulated the sulfate consumption rate with added sulfate reduced to a level below $0.01 \mathrm{~mm}$ in 2 weeks. Incubations of sediments supplied with ${ }^{13} \mathrm{C}$-labeled methane and sulfate did not result in the detectable production of ${ }^{13} \mathrm{C}$ enriched $\mathrm{CO}_{2}$ over a period of 6 months.

\section{Modeled consumption and production rates of sulfate and methane}

The reactive-transport modeling demonstrated that the net production of sulfate occurred at a rate of $5.38 \mathrm{~mm}$ per year within the top $6 \mathrm{~cm}$. The net consumption of sulfate proceeded at a rate of 


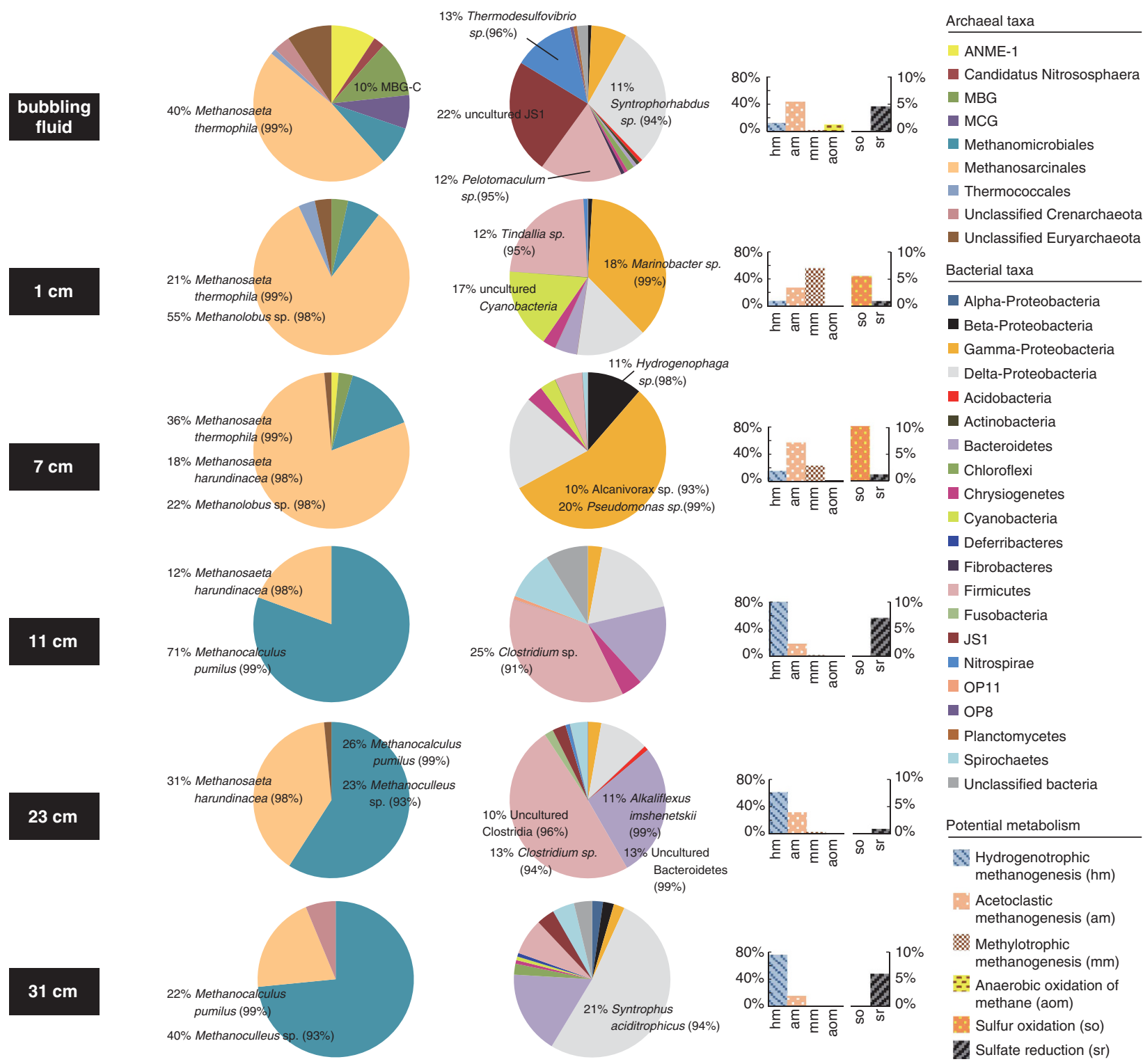

Figure 4 Bacterial and archaeal community structures in core c3 collected in 2009 based on the 16S rRNA gene analysis. Bacterial and archaeal communities are categorized by phylum and order, respectively. The fractions of the dominant phylotypes ( $>10 \%$ of each library), and their nearest culture representatives or environmental sequences are highlighted in the pie chart. The fractions of the phylotypes attributed to potential metabolisms (including methanogenesis, AOM, sulfate reduction and sulfur oxidation) are shown in the histograms. MBG stands for Marine Benthic Group, whereas MCG for Miscellaneous Crenarchaeal Group.

$2.16 \mathrm{~mm}$ per year at 6-14 cm (Supplementary Figure S3) and decreased from $0.49 \mathrm{~mm}$ per year at $14-22 \mathrm{~cm}$ to nearly zero at depths further below. The integrated rate fluxes of sulfate production (or sulfide oxidation) at the top $6 \mathrm{~cm}$ and sulfate reduction across the SMTZ were $3.16 \times 10^{-1}$ and $1.78 \times 10^{-1} \mathrm{~mol} \mathrm{~m}^{-2}$ per year, respectively. For comparison, the net methane consumption occurred at a rate of $0.82 \mathrm{~mm}$ per year or an integrated rate flux of $1.10 \times 10^{-1} \mathrm{~mol} \mathrm{~m}^{-2}$ per year at $\leqslant 14 \mathrm{~cm}$. The net methane production occurred at a rate of $0.79 \mathrm{~mm}$ per year or an integrated rate flux of $1.34 \times 10^{-1} \mathrm{~mol} \mathrm{~m}^{-2}$ per year at $\geqslant 14 \mathrm{~cm}$. If the transition from the net sulfate production to the net sulfate consumption is assumed to be the oxic-anoxic boundary, the integrated rate flux of aerobic and anaerobic methanotrophy would be $4.33 \times 10^{-2}$ and $6.66 \times 10^{-2}$ mol $\mathrm{m}^{-2}$ per year, respectively.

\section{Discussion}

Fluid transport and surface alteration

Fluids expelled from MVs are generally considered to rapidly migrate along the fracture tapping into 


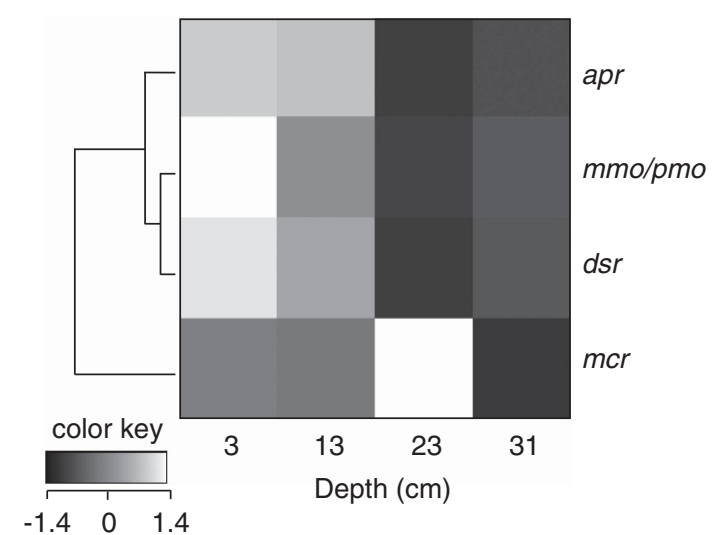

Figure 5 Heat map for pyrosequencing reads matching the genes apr, dsr, mmo/pmo and mcr. The Z-scores are scaled between -1.4 and 1.4, and assigned with different gray scales. The lighter the gray scale is, the greater the relative gene abundance is. The distances between genes are the Euclidean distance.

deep geological structures or reservoirs. Fluids and sediments released are subsequently deposited in the peripheral mud platform or drained toward the topographic depression, and subject to the alteration of surface processes. Therefore, fluids collected from mud pools or localized bubbling features could potentially constrain the compositions of deeply sourced fluid and surface processes. In this study, chloride conserved to microbial and most abiotic processes was first used as a tracer of fluid process. The chloride concentration in the top pore water was 1.6-1.9 times greater than that in the bubbling fluid. Such an enrichment of chloride concentration is best explained by surface evaporation. In addition, the isotopic compositions of fluids collected from the SYNHMV (Figure 1) and MVs in the adjacent areas (Supplementary Figure S1) deviated from the local meteoric water line at various degrees (Supplementary Figure S2), suggesting that these fluids are subject to the long-term water-rock interaction and surface evaporation (Wang et al., 2001). The interpretation of surface evaporation based on chloride concentrations and isotopic compositions are mutually consistent with each other. Second, the chloride concentration in the bottom pore water was comparable to that in the bubbling fluid (Figures 2a and 3a), suggesting that deeply sourced fluids are relatively less saline (100-120 mm chloride), and the variation of chloride in pore water could be attributed to the mixing between the deeply sourced, dilute component and the surface, saline component. Third, the enrichment of chloride in the top pore water was much less than that of sulfate (1.6 and 9.2 times for chloride and sulfate, respectively, in core c1; 1.9 and 276 times for chloride and sulfate, respectively, in core c2), suggesting that an additional sulfur source is required to enhance the sulfate concentration. The oxidation of fine-grained sulfide minerals (such as pyrite and greigite), previously identified in the host geological formation (Horng and Roberts, 2006),

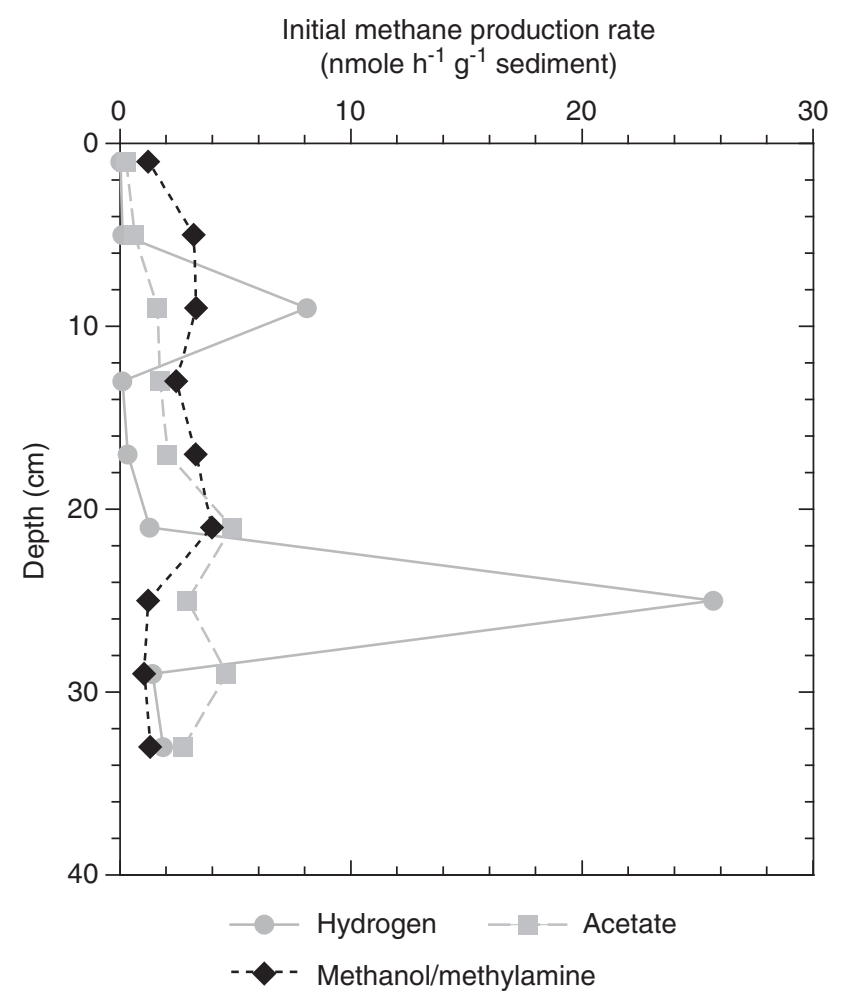

Figure 6 Initial methane production rates along the depth profile for incubations supplied with methanogenic precursors. for $\mathrm{H}_{2} / \mathrm{CO}_{2}$; for acetate; and $\bullet$ for methylamine/methanol.

appears to be the most plausible mechanism to account for the elevated sulfate concentration at the top interval. Whether this mineral oxidation is mediated by abiotic or microbial processes remains uncertain. The sulfate produced from evaporative condensation of solute and mineral oxidation is vital for microbial sulfate reduction at depth. Finally, the magnitude of sulfate depletion in pore water was much greater than that of chloride (Figures 2 and 3). The concentration profiles for compounds susceptible to microbial metabolisms could be readily distinguished from those controlled purely by abiotic processes.

\section{Geochemical and metabolic zonation}

The geochemical results obtained in this study reveal a stratified metabolic zonation pattern. Sulfate concentrations decreased from $>0.8 \mathrm{~mm}$ at the top to being nearly exhausted at $\sim 10 \mathrm{~cm}$ in both cores c1 and c2 (Figures 2 and 3). The decrease of sulfate was accompanied with the increase of methane with depth, marking a SMTZ. Like those observed in marine settings (Borowski et al., 1997; Treude et al., 2005), the observed SMTZ and geochemical profiles suggest active sulfate reduction, AOM and methanogenesis. The interpretation of the observed profiles is further supported by the decreasing $\delta^{13} \mathrm{C}$ values of methane with depth, the relative depletion of ${ }^{13} \mathrm{C}$ in methane in the 
methanogenic zone when compared with the bubbling fluid, and the coincidence of the smallest $\delta^{13} \mathrm{C}$-dissolved inorganic carbon values at the SMTZ.

The geochemical and metabolic stratification is apparently persistent over years (2007 vs 2009). Although chloride concentrations in the bubbling fluids collected in 2007 and 2009 remain nearly the same, the variation magnitudes of compounds susceptible to microbial metabolisms are timedependent. For example, sulfate concentrations were 0.8 and $4.1 \mathrm{~mm}$ in the top pore water obtained in 2007 and 2009, respectively (Figures 2 and 3). The difference in sulfate abundance could be accounted for by the duration of surface exposure of sediments to the atmosphere, the discharge frequency and magnitude of fluids and sediments, and the dilution caused by precipitation. Similarly, methane concentrations varied substantially within the methane-rich zone regardless of the cores analyzed, suggesting that methanogenesis is timeand depth-dependent, and heterogeneously distributed within the pore space.

Overall, surface processes and microbial activities exert a profound effect on the enrichment of sulfate in the top pore water and methane in the methanerich zones. Despite that the exact magnitude of variation in sulfate or methane abundance and the depth of SMTZ change temporarily, the metabolic stratification is persistently maintained at the SYNHMV. This is in contrast with the iron/manganese-methane transition signifying the metal-dependent AOM in a MV of eastern Taiwan (Chang et al., 2012) and exhibits great similarities with those commonly observed in marine counterparts. The presence of such a geochemical pattern and metabolic stratification seems to link to the strong depthdependent regulation imposed by the interactions between surface processes and subsurface fluid transport.

\section{Stratified community assemblages and functions}

The metabolic stratification inferred from geochemical profiles is consistent with the relative abundances of functional genes retrieved from the metagenome data and with the inference of $16 \mathrm{~S}$ rRNA gene sequences from the clone libraries. First, the abundances of reads matching the mmo/pmo and apr gene sequences decreased significantly with depth (Figure 5). In addition, abundant Alcanivorax-, Cyanobacteria-, Hydrogenophaga-, Marinobacter- and Pseudomonas-related 16S rRNA gene sequences were detected at 1 and $7 \mathrm{~cm}$ (Figure 4), and methane was aerobically consumed in all incubations. The gene mmo/pmo accounts for aerobic methane oxidation, whereas the gene apr represents the reversible conversion between sulfite and sulfate during either dissimilatory sulfate reduction or the oxidation of elemental sulfur or sulfide. Therefore, the enhanced abundance of these two genes at shallow depths together with the presence of sequences affiliated with oxygenic phototrophs and aerobic heterotrophs suggests that oxygen requiring microorganisms must proliferate above the transition zone where atmospheric oxygen could penetrate. Although the exact depth of oxygen penetration is not determined, the oxygen infiltrated from the atmosphere and produced by cyanobacteria would be transiently depleted by aerobic methanotrophy and/or heterotrophy, favoring the proliferation of anaerobes at depth.

In contrast, the presence of the genes $d s r$ and mcr indicates the capability for anaerobic sulfate reduction and methanotrophy/methanogenesis, respectively. The observed relative abundances of the genes, $d s r$ and mcr, exhibit inverse depth-dependent trends to each other (Figure 5), a pattern consistent with the geochemical interpretation that sulfate reduction and methanogenesis are primarily confined at the shallow depths and within the methanerich zone, respectively. The metagenome data is also in part corroborated with the detection of 16S rRNA gene sequences affiliated with Desulfobacterales and Desulfovibrionales within Delta-Proteobacteria, ANME-1 members, Methanomicrobiales and Methanosarcinales (Figure 4), and with the active sulfate reduction and methane production in the incubations.

Finally, to compare the communities from individual samples, the UniFrac program (Lozupone and Knight, 2005) with the Cluster Environments algorithm for the abundance-weighted phylotypes was employed. The bacterial and archaeal communities at depths above and below the SMTZ formed distinct clusters (Figure 7). The transition of both archaeal and bacterial communities at the SMTZ is consistent with the metabolic stratification inferred from the metagenome data. Such a community relationship supports the assertion that stratified microbial functions and community structures are strongly regulated by the geochemical context imposed by the interactions between surface processes and subsurface fluid transport.

The UniFrac analysis also indicated that the community assemblage in the bubbling fluid was distinct from those associated with the sediments (Figure 7). This combined with the observation that some sequences affiliated with thermophiles were either exclusively present or more abundant in the bubbling fluid suggests that a portion of community members might be derived from a deep source at high temperatures. The exposure of sediment to the atmosphere during the fluid discharge and sediment deposition would limit the survival of these indigenous thermophilic members, whereas rendering the proliferation of mesophiles potentially capable of adapting to the oxidative stress.

The majority of methanogen-related 16S rRNA gene sequences were related to Methanosarcinales (Methanosaeta- and Methanolobus-related strains; dominating at $\leqslant 7 \mathrm{~cm}$ ) and Methanomicrobiales (Methanoculleus- and Methanocalculus-related strains; 

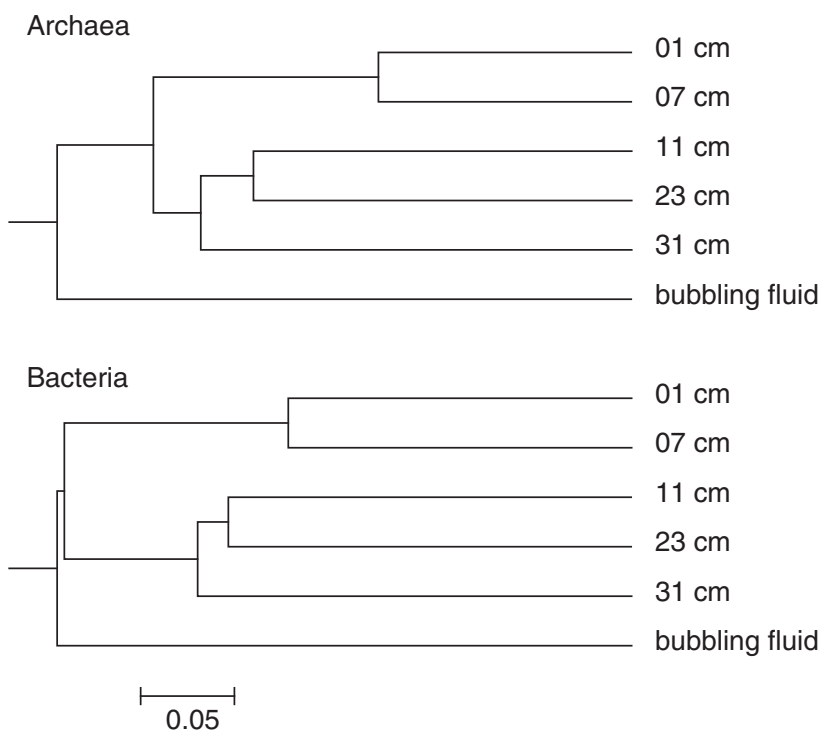

Figure 7 Community clustering based on the UniFrac analysis of 16S rRNA gene clone libraries. Scale bar shows the distance between each environmental sample.

dominating at $\geqslant 11 \mathrm{~cm}$; Figure 4). Methanolobus obligatorily utilizes non-competitive methyl compounds produced from the fermentation of osmoprotectants (such as glycerol) in hypersaline or saline environments (Zinder, 1993; Whitman et al., 2006). These methanogens could coexist with sulfate reducers without the need of substrate competition. Although the average chloride concentration in the top pore water does not exceed that of seawater, surface evaporation might lead to the local enhancement of salinity, thereby favoring the predominance of Methanolobus-related members at shallow depths. The activity of these methanogens would not be great, as methane is not substantially depleted in ${ }^{13} \mathrm{C}$ and methane concentrations are not enhanced at shallow depths. Methane produced in situ by these methanogens would be further consumed by aerobic and anaerobic methanotrophy.

Below $10 \mathrm{~cm}$, where sulfate was nearly exhausted, the Methanomicrobiales-related members outnumbered the other methanogens and likely produced methane through $\mathrm{CO}_{2}$ reduction. Methanogenic activities at these depth intervals are apparently high as evidenced by the high methane levels, the depletion of ${ }^{13} \mathrm{C}$ in methane and the maximum initial rates for the incubation of sediments at $25 \mathrm{~cm}$ with $\mathrm{H}_{2} / \mathrm{CO}_{2}$ (Figures 3 and 6). The high methanogenic activity has to be tied to the fermentative production of $\mathrm{H}_{2}$ through a syntrophic relationship by which hydrogenotrophic methanogens and hydrogen-producing fermenters maximize the efficiency of interspecies $\mathrm{H}_{2}$ transfer (Ishii et al., 2005; Kimura et al., 2010). These methanogens are most likely heterogeneously distributed within the methane-rich zone, thereby accounting for the fluctuating methane levels obtained from triplicate measurements.

\section{Conclusions}

Although metabolic stratification at the SYNHMV resembles that in marine counterparts, the driving force that charges the deeply sourced, oxidantdepleted fluids with sufficient amounts of electron acceptor is quite different. As no sulfate-rich seawater overlies sediments, the intrusion of atmospheric oxygen fuels aerobic methane/sulfide oxidation and transforms sulfide minerals into sulfate (Supplementary Figure S5). With the feedback of aerobic metabolisms, the dissolved oxygen would be transiently depleted to facilitate the colonization of anaerobes that harvest metabolic energy from either mineral-derived sulfate or organic carbon inherited in sediments. Methane flux generated by in situ methanogenesis appears to overprint the thermogenic methane migrating from deep sources quantitatively and isotopically, and to exceed the capacity of microbial consumption. Interpretations constrained by geochemical and molecular results demonstrate that tightly coupled carbon and sulfur cycles enable the link of deep crustal environments with surface microbial and abiotic processes in terrestrial MV ecosystems. Such surface-subsurface interactions would allow the creation of numerous micro-niches harboring various assemblages of specialized microorganisms modulated under specific geochemical contexts.

\section{Conflict of interest}

The authors declare no conflict of interest.

\section{Acknowledgements}

We thank the assistance of Jia-Jing Wu, Yu-Chen Ling, Yue-Ting Lin and Shao-Hsuan Lin for their contribution to experimental setup and field sampling. Support from National Science Council (NSC 100-2627-M-002-010) and National Taiwan University to P-LW and L-HL are acknowledged.

\section{References}

Abildgaard L, Nielsen MB, Kjeldsen KU, Ingvorsen K. (2006). Desulfovibrio alkalitolerans sp. nov., a novel alkalitolerant, sulphate-reducing bacterium isolated from district heating water. Int J Syst Evol Microbiol 56: 1019-1024.

Alain K, Holler T, Musat F, Elvert M, Treude T, Kruger M. (2006). Microbiological investigation of methane- and hydrocarbon-discharging mud volcanoes in the Carpathian Mountains, Romania. Environ Microbiol 8: 574-590.

Alazard D, Badillo C, Fardeau ML, Cayol JL, Thomas P, Roldan $\mathrm{T}$ et al. (2007). Tindallia texcoconensis sp. nov., a new haloalkaliphilic bacterium isolated from lake Texcoco, Mexico. Extremophiles 11: 33-39.

Ashelford KE, Chuzhanova NA, Fry JC, Jones AJ, Weightman AJ. (2005). At least 1 in 20 16S rRNA sequence record currently held in public repositories is estimated to contain substantial anomalies. Appl Environ Microbiol 71: 7724-7736. 
Boetius A, Ravenschlag K, Schubert C, Rickert D, Widdel F, Gieseke A et al. (2000). A marine microbial consortium apparently mediating anaerobic oxidation of methane. Nature 407: 623-626.

Borowski WS, Paull CK, Ussler Iii W. (1997). Carbon cycling within the upper methanogenic zone of continental rise sediments: an example from the methane-rich sediments overlying the Blake Ridge gas hydrate deposits. Mar Chem 57: 299-311.

Brinkhoff T, Muyzer G. (1997). Increased species diversity and extended habitat range of sulfur-oxidizing Thiomicrospira spp. Appl Environ Microbiol 63: 3789-3796.

Chang Y-H, Cheng T-W, Lai W-J, Tsai W-Y, Sun C-H, Lin L-H et al. (2012). Microbial methane cycling in a terrestrial mud volcano in eastern Taiwan. Environ Microbiol 14: 895-908.

Etiope G, Lassey KR, Klusman RW, Boschi E. (2008). Reappraisal of the fossil methane budget and related emission from geologic sources. Geophy Res Lett 35: L09307.

Etiope G, Feyzullayev A, Baciu CL. (2009). Terrestrial methane seeps and mud volcanoes: A global perspective of gas origin. Marine Petrol Geol 26: 333-344.

Henry E, Devereux R, Maki J, Gilmour C, Woese C, Mandelco L et al. (1994). Thermodesulfovibrio yellowstonii, gen. nov. and sp. nov.: its phylogenetic relationship to Thermodesulfobacterium commune and their origins deep within the bacterial domain. Arch Microbiol 161: 62-69.

Horng C-S, Roberts AP. (2006). Authigenic or detrital origin of pyrrhotite in sediments?: Resolving a paleomagnetic conundrum. Earth Planet Sci Lett 241: 750-762.

Huber H, Hohn MJ, Rachel R, Fuchs T, Wimmer VC, Stetter KO. (2002). A new phylum of Archaea represented by a nanosized hyperthermophilic symbiont. Nature 417: 63-67.

Imachi H, Sekiguchi Y, Kamagata Y, Hanada S, Ohashi A, Harada H. (2002). Pelotomaculum thermopropionicum gen. nov., sp. nov., an anaerobic, thermophilic, syntrophic propionate-oxidizing bacterium. Int J Syst Evol Microbiol 52: 1729-1735.

Ishii Si, Kosaka T, Hori K, Hotta Y, Watanabe K. (2005). Coaggregation facilitates interspecies hydrogen transfer between Pelotomaculum thermopropionicum and Methanothermobacter thermautotrophicus. Appl Environ Microbiol 71: 7838-7845.

Kämpfer P, Schulze R, Jäckel U, Malik KA, Amann R, Spring S. (2005). Hydrogenophaga defluvii sp. nov. and Hydrogenophaga atypica sp. nov., isolated from activated sludge. Int J Syst Evol Microbiol 55: 341-344

Kamagata Y, Kawasaki H, Oyaizu H, Nakamura K-I, Mikami E, Endo G et al. (1992). Characterization of three thermophilic strains of Methanothrix ("Methanosaeta") thermophila sp. nov. and rejection of Methanothrix ("Methanosaeta") thermoacetophila. Int J Syst Bacteriol 42: 463-468.

Kimura H, Nashimoto H, Shimizu M, Hattori S, Yamada K, Koba $\mathrm{K}$ et al. (2010). Microbial methane production in deep aquifer associated with the accretionary prism in Southwest Japan. ISME J 4: 531-541.

Knittel K, Boetius A. (2009). Anaerobic oxidation of methane: progress with an unknown process. Annu Rev Microbiol 63: 311-334.

Kopf AJ. (2004). Significance of mud volcanism. Rev Geophys 40: 1-52.
Kuever J, Rainey FA, Widdel F. (2005). (The Proteobacteria) part C (The Alpha-, Beta-, Delta-, and Epsilonproteobacteria). In: Brenner DJ, Krieg NR (eds). Bergey's Manual of Systematic Bacteriology, 2 edn. Springer: New York, pp 959-987.

Lane DJ. (1991). 16S/23S rRNA sequencing. In: Stackenbrandt E, Goodfellow M (eds). Nucleic Acid Techniques in Bacterial Systematics. Wiley: NY, pp 115-175.

Lepage E, Marguet E, Geslin C, Matte-Tailliez O, Zillig W, Forterre $\mathrm{P}$ et al. (2004). Molecular diversity of new Thermococcales isolates from a single area of hydrothermal deep-sea vents as revealed by randomly amplified polymorphic DNA fingerprinting and 16S rRNA gene sequence analysis. Appl Environ Microbiol 70: 1277-1286.

Lin L-H, Gihring T, Sherwood Lollar B, Boice E, Pratt L, Lippmann-Pipke J et al. (2006). Planktonic microbial communities associated with fracture-derived groundwater in a deep gold mine of South Africa. Geomicrobiol J 23: $475-498$.

Lozupone C, Knight R. (2005). UniFrac: a new phylogenetic method for comparing microbial communities. Appl Environ Microbiol 71: 8228-8235.

Milkov AV. (2004). Global estimates of hydrate-bound gas in marine sediments: how much is really out there? Earth-Sci Rev 66: 183-197.

Orphan VJ, House CH, Hinrichs K-U, McKeegan KD, DeLong EF. (2002). Multiple archaeal groups mediate methane oxidation in anoxic cold seep sediments. Proc Natl Acad Sci 99: 7663-7668.

Qiu Y-L, Hanada S, Ohashi A, Harada H, Kamagata Y, Sekiguchi Y. (2008). Syntrophorhabdus aromaticivorans gen. nov., sp. nov., the first cultured anaerobe capable of degrading phenol to acetate in obligate syntrophic associations with a hydrogenotrophic methanogen. Appl Environ Microbiol 74: 2051-2058.

RDC Team (R Development Core Team) (2008). $R$ : A language and environment for statistical computing. R Foundation for Statistical Computing: Vienna, Austria.

Shiratori H, Sasaya K, Ohiwa H, Ikeno H, Ayame S, Kataoka N et al. (2009). Clostridium clariflavum sp. nov. and Clostridium caenicola sp. nov., moderately thermophilic, cellulose-/cellobiose-digesting bacteria isolated from methanogenic sludge. Int J Syst Evol Microbiol 59: 1764-1770.

Sorokin DY, Tourova TP, Kolganova TV, Sjollema KA, Kuenen JG. (2002). Thioalkalispira microaerophila gen. nov., sp. nov., a novel lithoautotrophic, sulfuroxidizing bacterium from a soda lake. Int J Syst Evol Microbiol 52: 2175-2182.

Sun C-H, Chang S-C, Kuo C-L, Wu J-C, Shao P-H, Oung JH. (2010). Origins of Taiwan's mud volcanoes: evidence from geochemistry. J Asian Earth Sci 37: 105-110.

Treude T, Niggemann J, Kallmeyer J, Wintersteller P, Schubert C, Boetius A et al. (2005). Anaerobic oxidation of methane and sulfate reduction along the Chilean continental margin. Geochim Cosmochim Acta 69: 2767-2779.

Wang B, Lai Q, Cui Z, Tan T, Shao Z. (2008a). A pyrenedegrading consortium from deep-sea sediment of the West Pacific and its key member Cycloclasticus sp. P1. Environ Microbiol 10: 1948-1963.

Wang CH, Kuo CH, Peng TR, Chen WF, Liu TK, Chiang CJ et al. (2001). Isotope characteristics of Taiwan groundwaters. West Pac Earth Sci 1: 415-428. 
Wang G, Spivack AJ, Rutherford S, Manor U, D’Hondt S. (2008b). Quantification of co-occurring reaction rates in deep subseafloor sediments. Geochim Cosmochim Acta 72: 3479-3488.

Whiticar MJ. (1990). A geochemical perspective of natural gas and atmospheric methane. Org Geochem 16: $531-547$.

Whitman W, Bowen T, Boone D. (2006). The methanogenic bacteria. In: Dworkin M, Falkow S, Rosenberg E, Schleifer K-H, Stackebrandt E (eds) The Prokaryotes, 3rd edn. Springer-Verlag: New York, pp 165-207.

Wrede C, Brady S, Rockstroh S, Dreier A, Kokoschka S, Heinzelmann SM et al. (2012). Aerobic and anaerobic methane oxidation in terrestrial mud volcanoes in the Northern Apennines. Sediment Geol 263-264: 210-219.

Zhang W, Xue Y, Ma Y, Grant WD, Ventosa A, Zhou P. (2002). Marinospirillum alkaliphilum sp. nov., a new alkaliphilic helical bacterium from Haoji soda lake in Inner Mongolia Autonomous Region of China. Extremophiles 6: 33-37.

Zhilina TN, Appel R, Probian C, Brossa EL, Harder J, Widdel F et al. (2004). Alkaliflexus imshenetskii gen. nov. sp. nov., a new alkaliphilic gliding carbohydratefermenting bacterium with propionate formation from a soda lake. Arch Microbiol 182: 244-253.

Zhilina TN, Zavarzina DG, Kuever J, Lysenko AM, Zavarzin GA. (2005). Desulfonatronum cooperativum sp. nov., a novel hydrogenotrophic, alkaliphilic, sulfate-reducing bacterium, from a syntrophic culture growing on acetate. Int J Syst Evol Microbiol 55: 1001-1006.

Zinder SH. (1993). Physiological ecology of methanogens. In: Ferry JG (ed) Methanogenesis: Ecology, Physiology, Biochemistry and Genetics. Chapman and Hall: New York, pp 128-206.

Supplementary Information accompanies the paper on The ISME Journal website (http://www.nature.com/ismej) 